\title{
Orlistat accentuates the fat-induced fall in blood pressure in older adults
}

\author{
Kamilia Tai ${ }^{1}$, Diana Gentilcore ${ }^{1}$, Karen L. Jones ${ }^{1,2}$, Lisa Banh ${ }^{1}$, Odd Helge Gilja ${ }^{3}$, Angela J. Hammond ${ }^{1}$, \\ Christine Feinle-Bisset ${ }^{1,2}$, Michael Horowitz ${ }^{1,2}$ and Ian M. Chapman ${ }^{1,2 *}$ \\ ${ }^{1}$ Discipline of Medicine, Royal Adelaide Hospital, University of Adelaide, North Terrace, Adelaide, SA 5000, Australia \\ ${ }^{2}$ NHMRC Centre of Clinical Research Excellence in Nutritional Physiology, Interventions and Outcomes, Adelaide, SA, \\ Australia \\ ${ }^{3}$ Institute of Medicine, University of Bergen and National Centre for Ultrasound in Gastroenterology, Haukeland University \\ Hospital, Bergen, Norway
}

(Received 14 January 2010 - Revised 28 May 2010 - Accepted 30 July 2010 - First published online 14 March 2011)

\section{Abstract}

Postprandial hypotension may be influenced by the digestion of fat. The aim of the present study was to evaluate the hypothesis that products of fat digestion mediate the hypotensive response to fat. In part A of the study, nine healthy older subjects were studied on three separate occasions in randomised order. Blood pressure, heart rate (HR), plasma TAG and gastric emptying were measured following the ingestion of equivolaemic drinks: (1) $300 \mathrm{ml}$ of high-fat drink ( $88 \%$ fat); (2) fat drink mixed with $120 \mathrm{mg}$ orlistat (lipase inhibitor); (3) water (control). In part B of the study, ten healthy older subjects were studied on two separate occasions. Blood pressure, HR, plasma TAG and superior mesenteric artery flow were measured during $90 \mathrm{~min}$ intraduodenal infusions of $10 \%$ intralipid $(2 \cdot 7 \mathrm{ml} / \mathrm{min})$, with and without $120 \mathrm{mg}$ orlistat. Oral fat ingestion was associated with decreases in systolic and diastolic blood pressures (both $P=0 \cdot 0001)$ that were greater when orlistat was co-administered (both $P<0.05)$, and an increase in HR $(P=0.0001)$ that was inhibited by orlistat co-administration $(P<0.03)$. Gastric emptying was slowed by oral fat digestion, and orlistat administration inhibited this slowing $(P<0 \cdot 04)$. Intraduodenal fat infusion was not associated with changes in blood pressure but increased HR $(P<0 \cdot 0001)$, an effect attenuated by orlistat $(P<0 \cdot 05)$. In conclusion, orlistat potentiates the hypotensive response to oral fat in older adults, possibly as a result of faster gastric emptying of fat. The results do not support a role for fat digestion in lowering blood pressure.

\section{Key words: Postprandial hypotension: Fat: Cardiovascular function: Elderly}

Postprandial hypotension (PPH), defined as a decrease in systolic blood pressure (SBP) of $\geq 20 \mathrm{mmHg}$ within $2 \mathrm{~h}$ of the start of a meal ${ }^{(1)}$, occurs frequently in older adults and can result in significant morbidity, including an increased risk of falls and syncope ${ }^{(1-3)}$, coronary events, stroke and increased mortality $^{(4)}$. One approach to the prevention and treatment of PPH may be to alter the type of food eaten in favour of macronutrients, which minimise the fall in blood pressure. In the elderly, there is some evidence that carbohydrate ingestion reduces postprandial blood pressure more than other macronutrients ${ }^{(1,5)}$. Reports of the effects of fat ingestion on blood pressure in older subjects have been inconsistent, with some studies finding no fall ${ }^{(6-9)}$ or an increase ${ }^{(5)}$ or a delayed but similar fall in blood pressure compared with those of carbohydrate ingestion ${ }^{(10)}$. If fat ingestion has a less pronounced effect on blood pressure than carbohydrate ingestion, an approach to the management of $\mathrm{PPH}$ in affected older people may be to increase fat at the expense of carbohydrate in the diet.

Digestion of fat and carbohydrate is necessary for the full slowing of gastric emptying, stimulation of gut hormone release and suppression of appetite that follows the ingestion of these macronutrients in food ${ }^{(11,12)}$. It is not known, however, whether the digestion of carbohydrate and fat plays a role in the blood pressure fall that follows the ingestion of these macronutrients. This possibility is supported by the observation that acarbose, which inhibits disaccharide digestion to glucose, attenuates the blood pressure-lowering effect of oral sucrose in both elderly subjects and patients with $\mathrm{PPH}^{(13,14)}$

In the present study, orlistat, which inhibits lipase action and thus fat digestion in the gut, was used to examine the role of fat digestion in mediating fat-induced blood pressure decreases. We hypothesised that the products of fat digestion mediate the hypotensive response to fat, and that orlistat

Abbreviations: bpm, beats per min; DBP, diastolic blood pressure; HR, heart rate; PPH, postprandial hypotension; SBP, systolic blood pressure; T50, 50\% gastric emptying time.

*Corresponding author: Professor I. M. Chapman, fax +61 88223 3870, email ian.chapman@adelaide.edu.au 
would reduce the postprandial fall in blood pressure. If so, this might have therapeutic implications for the management of $\mathrm{PPH}$.

The use of orlistat in such a study is potentially complicated by its effects on gastric emptying and hence on gastric distension. The blood pressure-lowering effects of carbohydrates in food are dependent on small-intestinal nutrient exposure ${ }^{(15)}$ and are inhibited by gastric distension ${ }^{(16)}$. The faster the stomach empties, the greater the fall in blood pressure after oral glucose ingestion ${ }^{(17)}$. Co-administering orlistat with high-fat foods inhibits lipase action and fat digestion, and, as a result, accelerates gastric emptying and reduces gastric distension ${ }^{(11,18-21)}$. Both effects might be expected to enhance fat-induced postprandial falls in blood pressure and thus oppose a blood pressure-raising effect of the inhibition of fat digestion if one was present. To bypass the effects of fat and orlistat on both gastric distension and gastric emptying, we also administered lipid (with and without orlistat) intraduodenally.

\section{Methods}

\section{Subjects}

Part A - oral fat with or without orlistat. Of the healthy older subjects, nine (eight men and one woman), with a mean age of 73.2 (SEM 2.0) years (range 66-85 years) and a BMI of $25.9(\operatorname{sem~} 0.6) \mathrm{kg} / \mathrm{m}^{2}$ (range $23.0-28.8 \mathrm{~kg} / \mathrm{m}^{2}$ ), were recruited by advertisement.

Part B - intraduodenal fat (with or without orlistat) infusion. A total of ten healthy older subjects (five men and five women), with a mean age of 72.6 (SEm 1.1) years (range 66-77 years) and a BMI of $25 \cdot 1$ (SEM $0 \cdot 8) \mathrm{kg} / \mathrm{m}^{2}$ (range $21 \cdot 4-28 \cdot 8 \mathrm{~kg} / \mathrm{m}^{2}$ ), were recruited by separate advertisement.

All subjects were non-smokers, and none had a history of gastrointestinal disease or surgery, diabetes mellitus, significant respiratory, renal, hepatic or cardiac disease, autonomic dysfunction, chronic alcohol abuse or epilepsy. No subject was taking medication known to influence blood pressure or gastrointestinal function.

The present study was conducted according to the guidelines laid down in the Declaration of Helsinki, and all procedures were approved by the Research Ethics Committee of the Royal Adelaide Hospital. Written informed consent was obtained from all subjects. For part B of the study, we calculated that a minimum of five subjects per group would be required to detect a mean difference in a SBP of approximately $13 \mathrm{mmHg}$ with a power of $0 \cdot 80$, assuming a significance value $<0.05^{(10)}$.

\section{Study protocol}

Part A - oral fat with or without orlistat. Each subject was studied on three occasions, separated by at least $48 \mathrm{~h}$, in a single-blinded fashion. On each day, subjects attended the Discipline of Medicine, Royal Adelaide Hospital, at 08.30 hours following an overnight fast $(12 \mathrm{~h}$ for solids and $8.5 \mathrm{~h}$ for liquids). An intravenous cannula was placed in the left antecubital vein for blood sampling, and subjects were seated comfortably on a bed at approximately $90^{\circ}$, to mimic normal physiological conditions during a meal. An automated blood pressure cuff was placed around the right arm for the measurement of blood pressure and heart rate (HR).

On each of the study days, at $t=0 \mathrm{~min}$, subjects consumed the following equivolaemic drinks in randomised order: (1) water (control), $300 \mathrm{ml}$; (2) fat drink, $300 \mathrm{ml}$ total, comprising $110 \mathrm{ml}$ rich cream blended with $190 \mathrm{ml}$ full-fat milk (88\% fat, $7 \%$ carbohydrate, mostly lactose, 5\% protein; total energy $2732 \mathrm{~kJ}$ or $653 \mathrm{kcal}$ ), with low-energy flavouring; (3) fat-orlistat drink, $300 \mathrm{ml}$ total, made up of $110 \mathrm{ml}$ rich cream blended with $190 \mathrm{ml}$ full-cream milk, with low-energy flavouring, with crushed and dispersed contents of one $120 \mathrm{mg}$ capsule of orlistat (Xenical ${ }^{\circledR}$; F. Hoffmann-La Roche Limited, Basel, Switzerland). All of the drinks were consumed within 3 min at room temperature. The dose of $120 \mathrm{mg}$ orlistat was chosen, as it reduced SBP when administered with a meal in a previous study of patients with type 2 diabetes ${ }^{(21)}$.

Venous blood samples were obtained at baseline immediately before the ingestion of the drink $(t=-5$ and $-2 \mathrm{~min}$ ), at $15 \mathrm{~min}$ intervals for the first $60 \mathrm{~min}$, and then every $30 \mathrm{~min}$ until $t=181 \mathrm{~min}$. Blood samples were collected in ice-chilled dipotassium EDTA tubes containing $400 \mathrm{KIU}$ (kallikrein inactivator units) aprotinin/ml of blood (Trasylol; Bayer Australia Limited, Pymble, NSW, Australia). Plasma was separated by centrifugation $\left(3200 \mathrm{~g}, 15 \mathrm{~min}, 4^{\circ} \mathrm{C}\right)$ within $30 \mathrm{~min}$ of collection and stored at $-70^{\circ} \mathrm{C}$ until assayed.

Part B - intraduodenal fat with or without orlistat infusion. Each subject was studied on two occasions, separated by a minimum of $7 \mathrm{~d}$, in a single-blinded fashion. On each day, the subject attended the Discipline of Medicine, Royal Adelaide Hospital, at 08.30 hours following a fast $(10.5 \mathrm{~h}$ for solids and $8.5 \mathrm{~h}$ for liquids $)^{(13,22,23)}$. At that time, a silicone rubber catheter (external diameter approximately $4 \mathrm{~mm}$; Dentsleeve International Limited, Mui Scientific, Mississauga, ONT, Canada) was introduced into the stomach via an anaesthetised nostril $^{(22,24)}$. The assembly included an infusion channel (internal diameter approximately $1 \mathrm{~mm}$ ) and was positioned so that the infusion port was located approximately $10 \mathrm{~cm}$ distal to the pylorus (i.e. in the duodenum), as well as two other channels that were positioned in the antrum $(2.5 \mathrm{~cm}$ proximal to the pylorus) and duodenum $(2.5 \mathrm{~cm}$ distal to the pylorus), respectively, and were perfused with $0.9 \%$ saline. The correct positioning of the catheter was maintained by continuous measurement of the transmucosal potential difference between the antral $(-40 \mathrm{mV})$ and the duodenal $(0 \mathrm{mV})$ channel $^{(25)}$. For this purpose, an intravenous cannula filled with sterile saline was placed subcutaneously in the left forearm and used as a reference electrode ${ }^{(25)}$. The tip of the catheter passed into the duodenum by peristalsis, which took between 20 and $165 \mathrm{~min}$. Once the catheter was in position, the subject was placed in the recumbent position, and an automated blood pressure cuff was placed around the right $\operatorname{arm}^{(22,24)}$. Approximately $30 \mathrm{~min}$ after the catheter had been positioned correctly (at $t=0 \mathrm{~min}$ ), an intraduodenal infusion of fat $\left(10 \%\right.$ Intralipid $^{\circledR}$; Fresenius Kabi AB, Uppsala, 
Sweden) with or without $120 \mathrm{mg}$ orlistat in a volume of $243 \mathrm{ml}$ was begun and continued at a rate of $2.7 \mathrm{ml} / \mathrm{min}$ for $90 \mathrm{~min}$. On the two study days, saline $(0.9 \%)$ was infused intraduodenally at the same rate between $t=90$ and $150 \mathrm{~min}^{(26)}$. The fat infusions resulted in an energy delivery of $12.6 \mathrm{~kJ} / \mathrm{min}$ $(3 \mathrm{kcal} / \mathrm{min})$. Intraduodenal infusions were performed using a volumetric infusion pump (Gemini PC-1; IMED Corporation, San Diego, CA, USA). At $t=150 \mathrm{~min}$, the catheter and the intravenous cannula were removed, the subject was given a light meal and then allowed to leave the laboratory.

\section{Measurements}

Blood pressure and heart rate. SBP, diastolic blood pressure (DBP) and HR were measured using an automated oscillometric blood pressure monitor (DINAMAP ProCare 100; GE Medical Systems, Milwaukee, WI, USA). For part A of the study, two baseline measurements were taken at $t=-5$ and $-2 \mathrm{~min}$, before the ingestion of the drink at $t=0 \mathrm{~min}$, and subsequently, every $3 \mathrm{~min}$, between $t=-2$ and $91 \mathrm{~min}$, and then at $15 \mathrm{~min}$ intervals until $t=181 \mathrm{~min}$. For part $\mathrm{B}$, measurements were taken at $t=-9,-6$ and -3 min before the commencement of the intraduodenal infusions and, subsequently, every $3 \mathrm{~min}$, between $t=0$ and $150 \mathrm{~min}^{(22,24)}$.

'Baseline' (i.e. $t=0 \mathrm{~min}$ ) blood pressure and HR were calculated as the mean of measurements taken at $t=-5$ and $-2 \mathrm{~min}$ for part A of the study, and at $t=-9,-6$ and -3 min for part B of the study. PPH was defined as a fall in SBP of $\geq 20 \mathrm{mmHg}$ that was sustained for at least $30 \mathrm{~min}^{(1)}$.

Gastric emptying. For part A of the study, two-dimensional measurements of the antral area were performed using an Aloka SSD-650 CL Ultrasound Machine (Aloka Company, Limited Tokyo, Japan) with a $3 \cdot 5-5 \mathrm{MHz}$ sector transducer, as described and validated previously ${ }^{(27,28)}$. The area recorded during the fasted state was subtracted from the subsequent measurements made after a meal. Gastric emptying was expressed at any time point as $A_{\mathrm{C}(\mathrm{t})}=100-\left(\left(A_{(\mathrm{t})} /\right.\right.$ $\left.\left.A_{\max }\right) \times 100\right)$, where $A_{\mathrm{C}(\mathrm{t})}$ is the corrected antral area at a time point, $A_{(\mathrm{t})}$ is the area measured at a given time point, and $A_{\max }$ is the maximum antral area recorded after meal ingestion $^{(29)}$. The antral area was measured immediately before the drink $(t=0 \mathrm{~min}$ ), and at $5 \mathrm{~min}$ intervals until $15 \mathrm{~min}$, and then every $15 \mathrm{~min}$ until $t=180 \mathrm{~min}$.

\section{Superior mesenteric artery flow}

For part B of the study, superior mesenteric artery flow was measured by Duplex ultrasonography (i.e. B-mode and Doppler imaging) using a Logiq ${ }^{\text {TM }} 9$ ultrasonography system (GE Healthcare Technologies, Sydney, NSW, Australia), as described previously ${ }^{(30)}$. The subject was scanned using a $3.5 \mathrm{C}$ broad spectrum $2 \cdot 5-4 \mathrm{MHz}$ convex transducer ${ }^{(26,30)}$ at $t=-2,5$ and $10 \mathrm{~min}$ and then at $15 \mathrm{~min}$ intervals between $t=0$ and $150 \mathrm{~min}$. Blood flow $(\mathrm{ml} / \mathrm{min})$ was calculated immediately using the formula: $\pi \times r^{2} \times$ TAMV $\times 60$, where $r$ is the radius of the superior mesenteric artery and TAMV is the time-averaged mean velocity ${ }^{(30)}$.
Total TAG concentrations. Plasma total TAG concentrations were measured in stored $\left(-70^{\circ} \mathrm{C}\right)$ plasma samples. Samples obtained at $t=-2,90$ and $150 \mathrm{~min}$ were analysed. Plasma was processed on an Olympus 5400 analyser using TAG-liquid reagent (Integrated Sciences Private Limited, Willoughby, NSW, Australia) at the Institute of Medical and Veterinary Science Laboratories in Adelaide, SA, Australia ${ }^{(10)}$.

Cardiovascular autonomic nerve function. In both parts A and $\mathrm{B}$ of the study, cardiovascular autonomic nerve function was evaluated at the end of one of the study days, using standardised cardiovascular reflex tests ${ }^{(31,32)}$. Parasympathetic function was evaluated by the variation ( $\mathrm{R}-\mathrm{R}$ interval) of the HR during deep breathing and upon standing (ratio of the $\mathrm{R}-\mathrm{R}$ interval at approximately beat 30 to the $\mathrm{R}-\mathrm{R}$ interval at approximately beat 15). Sympathetic function was assessed by the fall in SBP in response to standing. Each test result was scored according to age-adjusted criteria as $0=$ normal, $1=$ borderline or $2=$ abnormal, for a total maximum score of 6 . A score of 3 or more was considered to indicate definite autonomic dysfunction $^{(31,32)}$.

\section{Statistical analysis}

The overall effects of treatment and time and the treatment $x$ time interactions on SBP, DBP and HR changes from baseline and from $t=-2$ to $181 \mathrm{~min}$ for part $\mathrm{A}$, and from $t=-2$ to $90 \mathrm{~min}$ and $t=90$ to $150 \mathrm{~min}$ for part $\mathrm{B}$ were assessed using two-way ANOVA. Superior mesenteric artery flow was assessed from $t=-2$ to $90 \mathrm{~min}$ and from $t=90$ to $150 \mathrm{~min}$. Total TAG concentrations were analysed as changes from baseline. The effects of time on SBP, DBP, HR, superior mesenteric artery flow, blood glucose and total TAG concentrations were analysed using one-way ANOVA. Post hoc, paired comparisons, using Student's $t$ test, adjusted for multiple comparisons by Bonferroni's correction, were performed if ANOVA showed significant effects. The maximum fall in blood pressure and maximum rise in HR were defined as the greatest mean change from baseline in each subject at any given time point for each treatment. In part A, comparisons of the effects of the drinks on blood pressure and HR in older subjects were analysed using repeated-measures three-way ANOVA, with time and treatment as factors. Relationships between the maximal decrease in SBP and the 50\% gastric emptying time (T50), and between the maximal increase in HR and T50 were assessed by Pearson's correlation analyses. All analyses were performed using Statview version 5.0 (SAS Institute, Inc., Cary, NC, USA). Data are expressed as means with their standard errors. A $P$ value of $<0.05$ was considered statistically significant.

\section{Results}

\section{Part A - oral fat with or without orlistat}

A total of twelve people were screened, of which nine were recruited. Of the excluded subjects, two were not willing to cease antihypertensive medications temporarily and one was enrolled in another research study at the time of screening. 
(a)

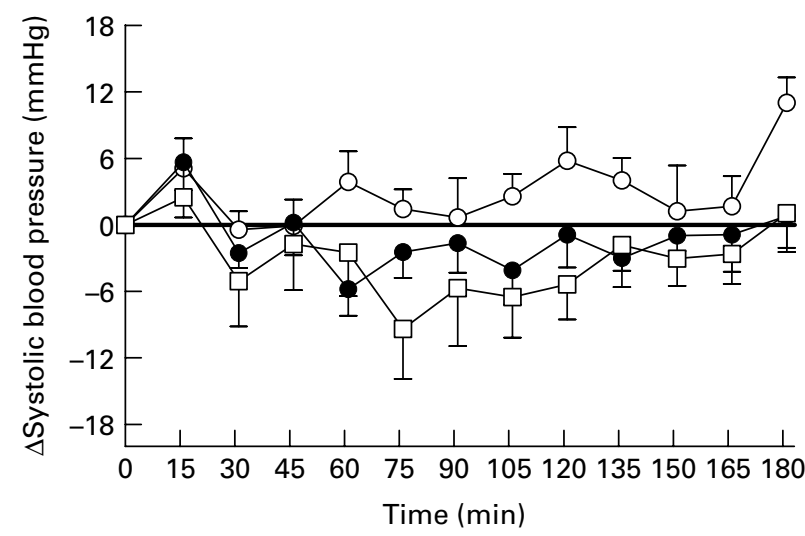

(b)

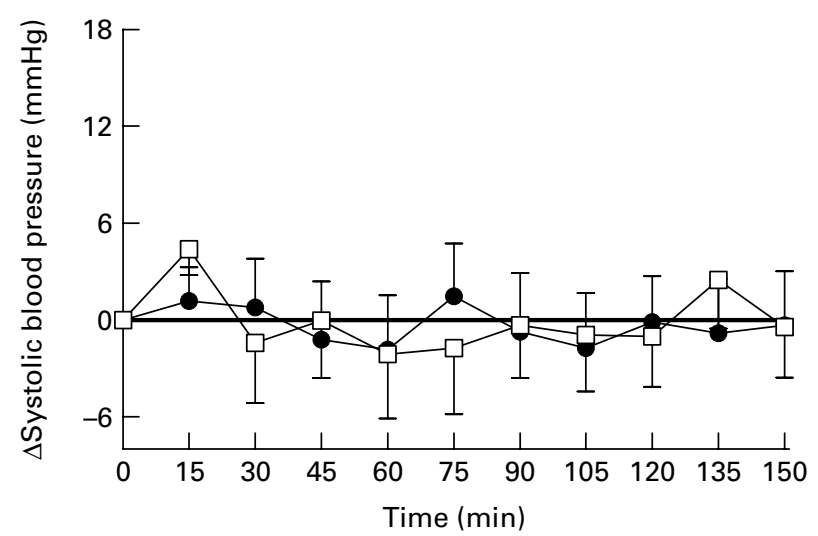

Fig. 1. Changes in systolic blood pressure from baseline in response to (a) the oral ingestion of water $(\bigcirc)$, fat $(\bullet)$ and fat-orlistat $(\square)$ drinks, and in response to (b) the intraduodenal infusion of fat and fat-orlistat in older subjects. Values are means, with standard errors represented by vertical bars.

None of the subjects had definite autonomic neuropathy; the median score for autonomic nerve dysfunction was 0 (range $0-2)$; two subjects had a score of 1 and one subject had a score of 2 .

The study drinks were well tolerated. After the fat-orlistat drink, oily stools and mild flatulence were reported by one subject. After the high-fat drink, one subject reported mild abdominal discomfort and nausea. In both cases, symptoms were mild and had resolved spontaneously within $19 \mathrm{~h}$ of drink ingestion.

Systolic blood pressure. There were no significant differences in baseline SBP between the three study days (fat drink 132.8 (SEM 4.8) mmHg $v$. fat-orlistat drink 131.6 (SEM 5.5) $\mathrm{mmHg} \quad v$. water 132.6 (SEM 4.8) $\mathrm{mmHg}$; Fig. 1(a)). However, one subject had PPH (i.e. a fall in SBP of $\geq 20 \mathrm{mmHg}$ sustained for $\geq 30 \mathrm{~min}$ ) following both the fat and fat-orlistat drinks. For SBP (change from baseline), there was no significant treatment effect $(P=0.07)$, but a significant time $(P=0.0001)$ effect and treatment $\times$ time interaction $(P=0.017)$ were found. SBP decreased progressively after the fat $(P=0.0001)$ and fat-orlistat $(P=0.0001)$ drinks, but not after the water drink $(P=0 \cdot 3)$. There was a greater reduction in SBP after the fat-orlistat drink than after the fat drink, which was significant between $t=73$ and $88 \mathrm{~min}$
$(P<0.05)$. The maximum fall in SBP during the fat $(16.3$ (SEM $2 \cdot 1) \mathrm{mmHg}$ ) and fat-orlistat (20.1 (SEM 3.9) $\mathrm{mmHg}$ ) drinks did not differ significantly $(P=0 \cdot 27)$, and there was also no significant difference in the time of maximum fall between the fat and fat-orlistat drinks (66.3 (SEM 14.5) v. 68.3 (SEM 10.6) min, $P=0 \cdot 9$ ).

Diastolic blood pressure. There were no significant differences in baseline DBP between the three study days (fat drink 74.2 (SEM 2.4) $\mathrm{mmHg} v$. fat-orlistat drink $75 \cdot 2$ (SEM 2.6) $\mathrm{mmHg}$ $v$. water 75.6 (SEM 2.5$) \mathrm{mmHg}$ ). For DBP (change from baseline), there were significant treatment $(P=0.007)$ and time $(P=0.0001) \quad$ effects and treatment $\times$ time interaction ( $P=0.0001)$ over the duration of the study. DBP decreased after the high-fat (maximum decrease of 9.6 (SEM 1.2) $\mathrm{mmHg}$, $P=0.0001)$ and the fat-orlistat (11.1 (sem 2.9) $\mathrm{mmHg}$, $P=0 \cdot 0001)$ drinks, but not after the water drink $(P=0 \cdot 31)$. There was a slight, but significantly greater, reduction in DBP following the ingestion of the fat-orlistat drink than after the fat drink $(P<0.05)$, with a maximal fall in DBP of 11.1 v. $9.6 \mathrm{mmHg}$, respectively.

Heart rate. There were no significant differences in baseline HR between the three study days (fat drink 59.7 (SEM 1.4) beats per min (bpm) $v$. fat-orlistat drink 57.8 (sEM 1.8) bpm $v$. water $59 \cdot 2$ (SEM 1.1) bpm; Fig. 2(a)). For HR
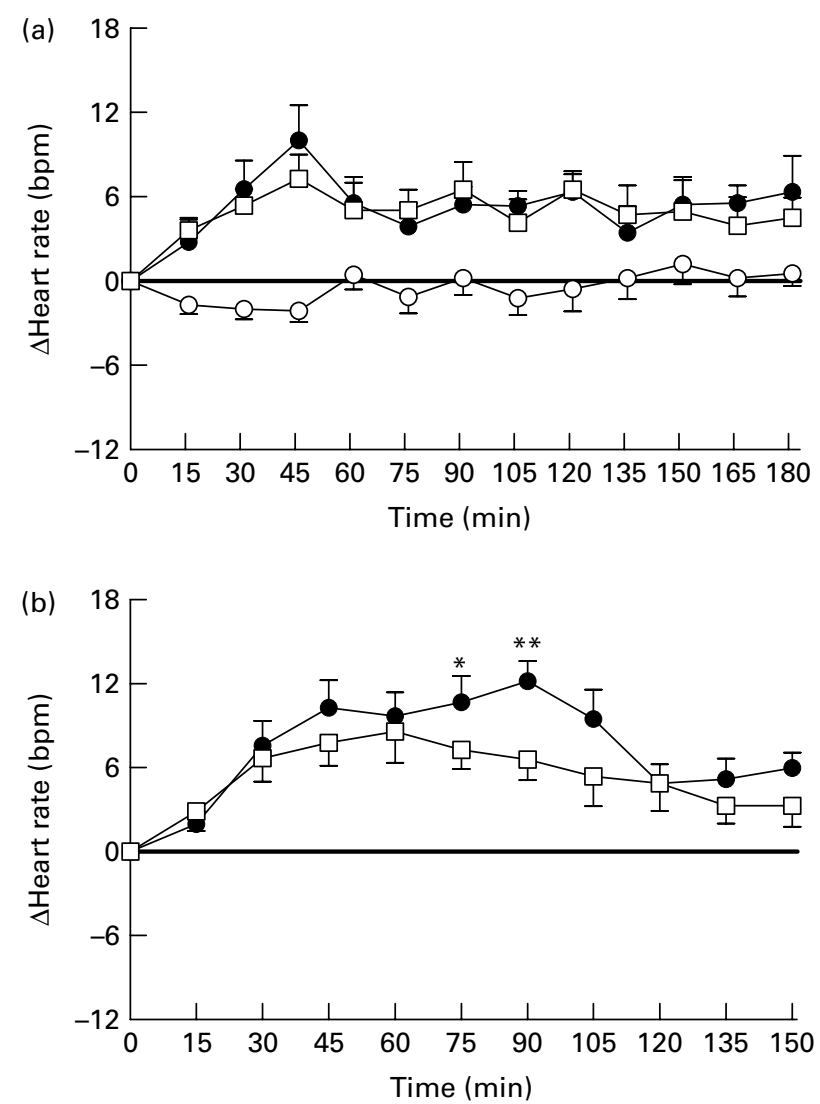

Fig. 2. Changes in heart rate (beats per $\min (\mathrm{bpm})$ ) from baseline in response to $(a)$ the oral ingestion of water $(\bigcirc)$, fat $(\bullet)$ and fat-orlistat $(\square)$ drinks, and in response to (b) the intraduodenal infusion of fat and fat-orlistat in older subjects. Values are means, with standard errors represented by vertical bars. Mean values were significantly different for treatment $\times$ time effect (fat $v$. fat-orlistat): ${ }^{*} P<0.05,{ }^{*} P<0.001$. 


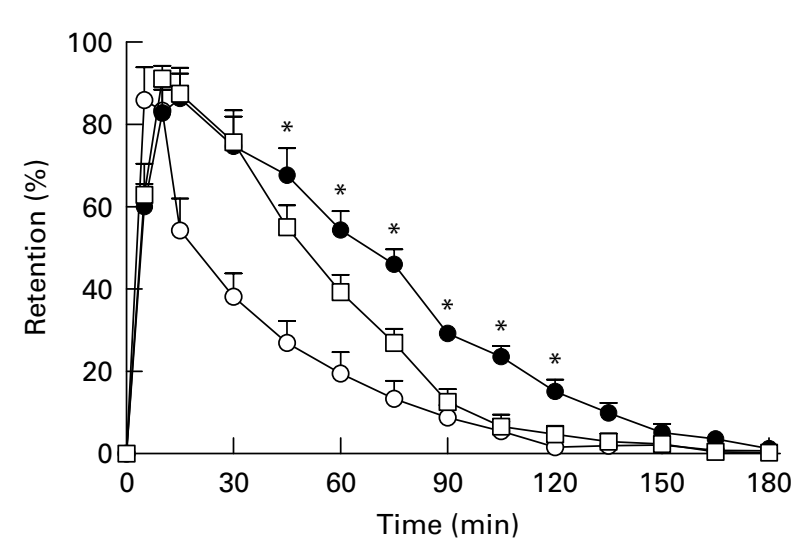

Fig. 3. Gastric emptying of water $(\bigcirc)$, fat $(\bullet)$ and fat-orlistat $(\square)$ drinks. Values are means, with standard errors represented by vertical bars. Mean values were significantly different for treatment $\times$ time effect (fat $v$. fat-orlistat): ${ }^{\star} P<0.04$

(change from baseline), there were significant treatment $(P=0 \cdot 0001)$ and time $(P=0 \cdot 0001)$ effects, and treatment $\times$ time interaction $(P=0.0001)$. HR increased after both the fat $(P=0.0001)$ and fat-orlistat $(P=0.0001)$ drinks, and decreased non-significantly after the water drink $(P=0 \cdot 09)$. The increase in HR was slightly greater following the fat drink than after the fat-orlistat drink, but only at 55 and $58 \mathrm{~min}(P<0.03)$. The maximum rise in HR during the fat (14.8 (SEM 2.6) bpm) and fat-orlistat (10.9 (sem 1.6) bpm) drinks did not differ significantly $(P=0 \cdot 13)$, and there was also no significant difference in the time to maximum rise in HR between the fat and fat-orlistat drinks (79.3 (sem 16.5) v. 71.7 (sem 13.9) min, $P=0.63$ ).

Gastric emptying. Gastric emptying of water was faster than that of the fat-orlistat drink, which was in turn faster than that of the fat drink (treatment effect, $P=0.0004$; Fig. 3). Gastric emptying was significantly faster after the fat-orlistat drink than after the fat drink from $t=45$ to $120 \mathrm{~min}$ $(P<0.04)$. There was no difference before that time. The T50 for the fat drink was greater compared with water $(60.3$ (SEM 7.1) v. $24 \cdot 7$ (SEM 5.8) $\mathrm{min}$, respectively, $P=0 \cdot 0003)$ and non-significantly greater than the fat-orlistat drink ( 47.4 (SEM 5.0) $\min , P=0 \cdot 24$ ).

Relationships between gastric emptying, blood pressure and heart rate. There were no significant relationships between the maximum fall in SBP and the T50 after either the fat-orlistat drink $(R-0.24, P=0.54)$ or the fat drink $(R$ $-0.08, P=0.85)$. There was a significant relationship between the maximum rise in HR and the T50 after the fat-orlistat drink ( $R 0.83, P=0.006)$, but not after the fat drink $(R 0 \cdot 17, P=0.65)$.

Total TAG concentrations. There was no difference in baseline total TAG concentrations between the three study days $(P=0 \cdot 72)$. TAG concentrations did not change from baseline after the water drink. There was a rise in total TAG concentrations after both the fat and treatment fat-orlistat $(P<0.001)$ infusions. At $90 \mathrm{~min}$, change from baseline TAG concentrations was not significantly different between the fat and fat-orlistat treatment days, although it was nonsignificantly greater on the fat treatment day (0.46 (SEM $0 \cdot 14)$ v. $0 \cdot 11(0 \cdot 14) \mathrm{mmol} / \mathrm{l}, P>0 \cdot 05)$.

\section{Part B - intraduodenal fat with or without orlistat infusion}

A total of ten people were screened, and all were recruited. The median score for autonomic nerve dysfunction was $1 \cdot 0$ (range $0-4$ ); one of the ten subjects had definite autonomic dysfunction. While the studies were well tolerated, eight of the ten subjects reported adverse effects after completion of the intraduodenal infusions. Loose stools or diarrhoea were experienced by six subjects after completion of the fat $(n 4)$ or fat-orlistat ( $n$ 3) infusion. Of the ten subjects, one reported abdominal cramps and two experienced fatigue after completion of the fat-orlistat infusion. In all cases, adverse effects were mild and resolved spontaneously by the following day. $\mathrm{PPH}$ (i.e. a fall in SBP of $\geq 20 \mathrm{mmHg}$ sustained for at least 30 min) was evident in two subjects; in one subject during both infusions and in the other during the fat infusion only. In one subject, total TAG concentrations could not be measured as intravenous cannulation was not possible.

Systolic blood pressure. There was no significant difference in baseline SBP between the $2 \mathrm{~d}$ (fat $v$. fat-orlistat infusion): $125 \cdot 8$ (SEM 5.4) $v .126 \cdot 2(5.9) \mathrm{mmHg}(P=0.85)$. Between $t=0$ and $90 \mathrm{~min}$, there was no difference in SBP between the $2 \mathrm{~d}(P=0.94)$. There were also no significant changes in SBP during the fat $(P=0.62)$ or fat-orlistat $(P=0.35)$ infusion. The maximum falls in SBP from baseline during the fat $(11.7$ (SEM 2.8$) \mathrm{mmHg}$ ) and fat-orlistat $(12.7$ (sEM 3.3) $\mathrm{mmHg}$ ) infusions were comparable $(P=0.51$; Fig. 1(b)).

Between $t=90$ and $150 \mathrm{~min}$, there was no significant difference in SBP between the $2 \mathrm{~d}(P=0 \cdot 71)$, nor were there any significant changes in SBP during the fat $(P=0 \cdot 83)$ or fat-orlistat $(P=0.94)$ infusion. At $t=150 \mathrm{~min}, \mathrm{SBP}$ was not significantly different from baseline after the fat $(P=0.87)$ or fat-orlistat $(P=0.94)$ infusion (Fig. 1(b)).

Diastolic blood pressure. There was no significant difference in baseline DBP between the $2 \mathrm{~d}$ (fat $v$. fat-orlistat infusion): $67.1(\operatorname{sem~3.4)~v.~} 68.0(3.2) \mathrm{mmHg}(P=0.41)$. Between $t=0$ and $90 \mathrm{~min}$, there was no significant difference in DBP between the $2 \mathrm{~d}(P=0.59)$. There was a trend $(P=0.08)$ for a fall in DBP during the fat, and DBP fell during the fat-orlistat $(P<0 \cdot 02)$ infusion.

Between $t=90$ and $150 \mathrm{~min}$, there was no significant difference in DBP between the $2 \mathrm{~d}(P=0.93)$. There were also no significant changes in DBP during the fat $(P=0.52)$ or fatorlistat $(P=0 \cdot 44)$ infusion. At $t=150 \mathrm{~min}$, there was no difference in DBP from baseline after the fat $(P=0.98)$ or fat-orlistat $(P=0.92)$ infusion.

Heart rate. There was no significant difference in baseline HR between the $2 \mathrm{~d}$ (fat $v$. fat-orlistat infusion): 55.9 (SEM 2.4) $v .56 .7(2.2) \mathrm{bpm}(P=0.45)$. There was a rise in HR during both the fat and fat-orlistat $(P<0.0001$ for both) infusions. The maximum increases in HR during the fat (16.0 (SEM 1.9) bpm) and fat-orlistat (18.2 (SEM 2.9) bpm) infusions were comparable $(P=0 \cdot 48)$, but between $t=0$ and $90 \mathrm{~min}$, there was a significant treatment $\times$ time effect $(P<0.05)$. HR was higher $(P<0.05)$ between $t=75$ and 90 min during the fat infusion, when compared with the fat-orlistat infusion (Fig. 2(b)). 
After $90 \mathrm{~min}$, HR decreased during both infusions. Between $t=90$ and $150 \mathrm{~min}$, there was no significant difference in HR between the $2 \mathrm{~d}(P=0 \cdot 11)$. HR fell $(P<0 \cdot 0001)$ during the fat infusion, and there was a trend $(P=0.08)$ for a fall in HR during the fat-orlistat infusion $(P=0 \cdot 08)$. At $t=150 \mathrm{~min}$, HR was greater than baseline after the fat infusion $(P=0.0001)$, and there was a trend $(P=0.06)$ for HR to be greater than baseline after the fat-orlistat infusion (Fig. 2(b)).

Superior mesenteric artery flow. There was a trend for a difference in baseline (i.e. $t=-2 \mathrm{~min}$ ) superior mesenteric artery flow between the $2 \mathrm{~d}$ (fat $v$. fat-orlistat: 588.9 (SEM 58.1) v. $708.2(\operatorname{sem} 80 \cdot 4) \mathrm{ml} / \mathrm{min} ; P=0.07)$. There was a rise in superior mesenteric artery flow during both the fat and fat-orlistat infusions $(P<0.0001$ for both), which was evident from $t=15 \mathrm{~min}$ ( $P<0.05$ for both). Between $t=-2$ and $90 \mathrm{~min}$, there was a significant treatment $\times$ time effect $(P<0.006)$ for superior mesenteric artery flow. Superior mesenteric artery flow was higher $(P<0.05)$ between $t=60$ and 90 min during the fat infusion, when compared with the fat-orlistat infusion (Fig. 4).

Between $t=90$ and $150 \mathrm{~min}$, there was no significant difference in superior mesenteric artery flow between the $2 \mathrm{~d}$ $(P=0 \cdot 16)$. There was a fall in superior mesenteric artery flow during both the fat $(P<0.0001)$ and fat-orlistat $(P<0.0002)$ infusions, which was evident from $t=120 \mathrm{~min}(P=0.0001)$ during the fat infusion and from $t=105 \mathrm{~min}(P=0.03)$ during the fat-orlistat infusion. At $t=150 \mathrm{~min}$, superior mesenteric artery flow was greater than baseline after both the fat $(P=0 \cdot 01)$ and fat-orlistat $(P=0 \cdot 05)$ infusions (Fig. 4).

Total TAG concentrations. There was a trend for a difference in baseline (i.e. $t=-2 \mathrm{~min}$ ) total TAG concentrations between the $2 \mathrm{~d}$ (fat $v$. fat-orlistat): $1 \cdot 1$ (SEM 0.13) v. 0.87 (SEM $0.09) \mathrm{mmol} / \mathrm{l}(P=0.07)$.

Between $t=-2$ and $150 \mathrm{~min}$, there was no difference in total TAG concentrations between the two study days $(P=0.62)$. However, there was a rise in total TAG concentrations after both the fat and fat-orlistat infusions $(P<0.0001$ for both). At $t=150 \mathrm{~min}$, total TAG concentrations were greater than baseline after both the fat and fat-orlistat infusions $(P<0.0001$ for both).

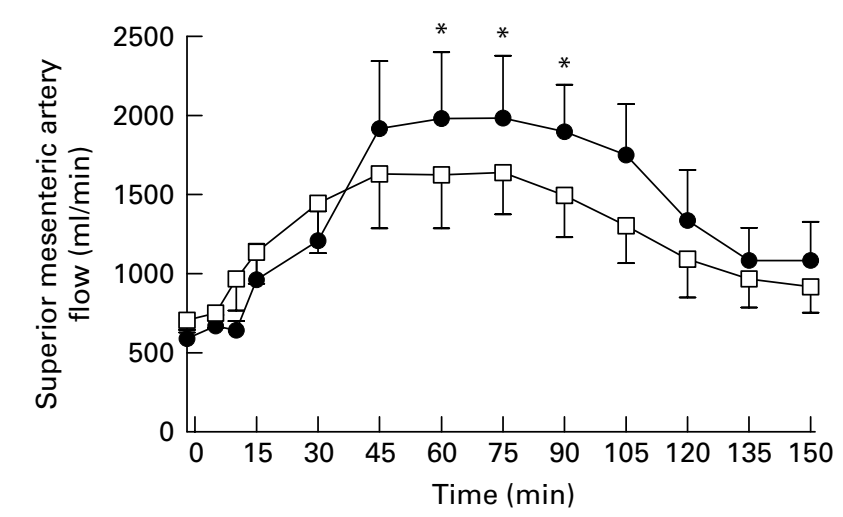

Fig. 4. Superior mesenteric artery flow in older subjects in response to the intraduodenal infusion of fat $(\bullet)$ and fat-orlistat $(\square)$ drinks. Values are means, with standard errors represented by vertical bars. Mean values were significantly different for treatment $\times$ time effect (fat $v$. fat-orlistat): ${ }^{*} P<0.05$.

\section{Discussion}

We confirmed that orlistat accelerated gastric emptying of fat, as found in previous studies ${ }^{(11,18-21)}$. The novel observations are that (1) orlistat potentiated the hypotensive response to oral fat in older subjects, possibly due to faster gastric emptying of fat and (2) the hypotensive effect of fat appeared not to depend on fat digestion.

Oral ingestion of a high-fat drink resulted in an increased HR and significant decreases in both systolic and DBP, with mean falls of approximately 8 and $6 \mathrm{mmHg}$, respectively. These blood pressure falls are consistent with the results of some ${ }^{(8,10)}$, but not all ${ }^{(5,7)}$, studies. The increase in HR probably reflects the activation of a baroreceptor reflex; as splanchnic blood flow increases after a meal, thus reducing systemic vascular resistance, there is a compensatory increase in HR. While possible, it seems very unlikely that the fall in blood pressure after fat ingestion was due to the small amount of carbohydrate in the drink (mainly lactose, $7 \%$ of total energy, $192 \mathrm{~kJ}$ ). Intraduodenal infusion of a greater amount of carbohydrate (glucose at $4.2 \mathrm{~kJ} / \mathrm{min}(1 \mathrm{kcal} / \mathrm{min})$ for $60 \mathrm{~min}$, $251 \mathrm{~kJ}$ ) than that used in the present study does not decrease blood pressure in older adults, whereas a greater glucose load of $12.6 \mathrm{~kJ} / \mathrm{min}(3 \mathrm{kcal} / \mathrm{min})$ for $60 \mathrm{~min}$ has a substantial effect $^{(24)}$. Our group has shown that healthy older adults experience comparable blood pressure decreases after oral or intraduodenal fat administration to those after equienergetic oral $^{(10)}$ or intraduodenal ${ }^{(26)}$ carbohydrate administration. It seems unlikely, therefore, that dietary modification, by altering the ratio of carbohydrate to fat content in a meal, has the potential to ameliorate the postprandial fall in blood pressure in older individuals with, or at risk of, $\mathrm{PPH}$.

While the results of the present study do not conclusively answer the question of whether fat digestion is required for its hypotensive effect, they suggest that it is not, although the extent of digestion of fat may modify the cardiovascular response to its ingestion. Fat digestion (lipolysis of TAG to fatty acids) is required for its appetite-suppressant effect $^{(33,34)}$, for the stimulation of cholecystokinin, glucagonlike peptide and peptide tyrosine-tyrosine ${ }^{(33,35)}$, suppression of ghrelin(36), slowing of gastric emptying ${ }^{(18,20,37)}$ and pancreatic enzyme secretion ${ }^{(35)}$. When orlistat was coadministered with oral fat in part A of the study, there was a slight, but significant, enhancement of the fat-induced decrease in both systolic and DBP, the opposite of what would be expected if products of fat digestion lowered blood pressure. Co-administration of orlistat with intraduodenal fat had no effect on blood pressure in part B of the study. In contrast, orlistat produced a slight but significant inhibition of the fatinduced pulse rate increase in both parts of the study. This is consistent with fat digestion being at least partly responsible for the increase in HR induced by fat ingestion. Similarly, the inhibition of fat-induced increased splanchnic blood flow after intraduodenal orlistat co-administration favours a role of fat digestion in this process.

The results of part A of the study do not exclude a role for fat digestion in fat-induced hypotension, as the hypotensive effect of faster gastric emptying due to orlistat may overshadow 
a weaker effect of orlistat to block the formation of hypotensive fat digestion products. Gastric emptying was slower after the high-fat drink compared with water, a finding consistent with previous studies ${ }^{(38)}$. It has previously been demonstrated that the fall in postprandial blood pressure is directly related to the rate of gastric emptying in individuals with type 2 diabetes ${ }^{(17)}$; when gastric emptying is slowed, the rate of delivery of nutrients to the small intestine, and thus nutrient-driven effects on blood pressure, is delayed. The acceleration of gastric emptying produced by orlistat therefore delivers fat to the small intestine more rapidly, thus presumably enhancing its hypotensive effects, and also reduces gastric distension, which would have the same effect. Although it is known that the stomach empties at a relatively constant rate of $8.4-12.6 \mathrm{~kJ} / \mathrm{min}(2-3 \mathrm{kcal} / \mathrm{min})^{(39)}$, the fat and fatorlistat drinks were emptied at faster rates of $16 \cdot 7-25 \cdot 1 \mathrm{~kJ} / \mathrm{min}$ ( $4-6 \mathrm{kcal} / \mathrm{min}$ ), suggesting that the intragastric fat may have separated from the aqueous component ${ }^{(40)}$. Part $\mathrm{B}$ of the study allowed examination of the effects of fat digestion more directly, as administration of fat and orlistat directly into the duodenum removed any effects on the rate of gastric emptying. DBP decreased from baseline after intraduodenal fat infusion, as in our previous study in older adults ${ }^{(26)}$. In the same study ${ }^{(26)}$, SBP decreased after fat infusion only when compared with the effects of a saline infusion, which we did not include in the present study for logistical reasons. In that study ${ }^{(26)}$, the effects of fat on DBP were most marked between 90 and $120 \mathrm{~min}$, whereas DBP was maximally reduced before $90 \mathrm{~min}$ in the present study. The reason for this difference is not apparent.

The absence in part B of the study of any effect of orlistat co-administration on the fat-induced decrease in DBP argues against a role of fat digestion in this blood pressure effect. This may, however, reflect the limited inhibition of fat digestion produced by orlistat with intraduodenal infusion. The increase in plasma TAG concentrations (the result of fat digestion) produced by fat, administered orally or intraduodenally, was only slightly, and not significantly, inhibited by orlistat coadministration. There are limitations in using plasma TAG concentrations to assess lipase inhibition ${ }^{(41-43)}$, and alternative measurements, such as daily faecal fat excretion, may be needed $^{(44,45)}$. It is possible that administration of a higher orlistat dose, or more vigorous mixing with the intralipid solution, would have produced greater lipase inhibition and permitted better examination of the role of fat digestion on blood pressure and HR in part B of the study. Nevertheless, there was no evidence of an orlistat effect on blood pressure, whereas there was a significant inhibitory effect on HR, suggesting a hierarchy of sensitivities, with HR being more readily affected by products of fat digestion than is blood pressure. This warrants further investigation.

In summary, these findings do not support a role for the products of fat digestion in mediating the blood pressurelowering effect of fat. Orlistat cannot, therefore, be used to attenuate the hypotensive response to a meal in older individuals, while manipulation of the composition of a meal, in particular its carbohydrate and fat content, also seems unlikely to be of benefit.

\section{Acknowledgements}

The present study was supported by the National Health and Medical Research Council (NHMRC) of Australia (project grant ID 453650), by an NHMRC of Australia postgraduate scholarship (ID 340310, to K. T.), by a National Heart Foundation of Australia Postdoctoral Fellowship (PR 07A 3309, to D. G.), by an NHMRC/Diabetes Australia Career Development Award (ID 250453, to K. L. J.), by an NHMRC of Australia Career Development Award (grant no. 299074, to C. F.-B.), by an Equipment Grant from the NHMRC of Australia (ID 219354) and by the University of Adelaide and GE Medical Systems Australia for the purchase of the Logiq ${ }^{\mathrm{TM}} 9$ ultrasonography system. We thank Nancy Briggs (Department of Public Health, University of Adelaide) for her assistance with the statistical analyses. The authors' contributions were as follows: K. T. and D. G. were responsible for the acquisition of subjects, data collection, analysis, interpretation and preparation of the manuscript; K. L. J., M. H. and I. M. C. had a primary role in the concept and design of the study, data interpretation and preparation of the manuscript; L. B. and A. J. H. collected the data; O. H. G. supervised the data collection, analysis and interpretation; C. F.-B. assisted in the data interpretation and preparation of the manuscript. None of the authors had any personal or financial conflict of interest.

\section{References}

1. Jansen RW \& Lipsitz LA (1995) Postprandial hypotension: epidemiology, pathophysiology, and clinical management. Ann Intern Med 122, 286-295.

2. Puisieux F, Bulckaen H, Fauchais AL, et al. (2000) Ambulatory blood pressure monitoring and postprandial hypotension in elderly persons with falls or syncopes. $J$ Gerontol $A$ Biol Sci Med Sci 55, M535-M540.

3. Aronow WS \& Ahn C (1994) Postprandial hypotension in 499 elderly persons in a long-term health care facility. $J$ Am Geriatr Soc 42, 930-932.

4. Aronow WS \& Ahn C (1997) Association of postprandial hypotension with incidence of falls, syncope, coronary events, stroke, and total mortality at 29-month follow-up in 499 older nursing home residents. J Am Geriatr Soc $\mathbf{4 5}$, 1051-1053.

5. Potter JF, Heseltine D, Hartley G, et al. (1989) Effects of meal composition on the postprandial blood pressure, catecholamine and insulin changes in elderly subjects. Clin Sci (Lond) 77, 265-272.

6. Heseltine D, Potter JF, Hartley G, et al. (1990) Blood pressure, heart rate and neuroendocrine responses to a high carbohydrate and a high fat meal in healthy young subjects. Clin Sci (Lond) 79, 517-522.

7. Jansen RW, Peeters TL, Van Lier HJ, et al. (1990) The effect of oral glucose, protein, fat and water loading on blood pressure and the gastrointestinal peptides VIP and somatostatin in hypertensive elderly subjects. Eur J Clin Invest 20, 192-198.

8. Sidery MB, Cowley AJ \& MacDonald IA (1993) Cardiovascular responses to a high-fat and a high-carbohydrate meal in healthy elderly subjects. Clin Sci (Lond) 84, 263-270.

9. Sidery MB, Macdonald IA, Cowley AJ, et al. (1991) Cardiovascular responses to high-fat and high-carbohydrate meals in young subjects. Am J Physiol 261, H1430-H1436.

10. Visvanathan R, Horowitz M \& Chapman I (2006) The hypotensive response to oral fat is comparable but slower 
compared with carbohydrate in healthy elderly subjects. $\mathrm{Br}$ J Nutr 95, 340-345.

11. Pilichiewicz A, O'Donovan D, Feinle C, et al. (2003) Effect of lipase inhibition on gastric emptying of, and the glycemic and incretin responses to, an oil/aqueous drink in type 2 diabetes mellitus. J Clin Endocrinol Metab 88, 3829-3834.

12. Feinle C, Rades T, Otto B, et al. (2001) Fat digestion modulates gastrointestinal sensations induced by gastric distention and duodenal lipid in humans. Gastroenterology 120, 1100-1107.

13. Gentilcore D, Bryant B, Wishart JM, et al. (2005) Acarbose attenuates the hypotensive response to sucrose and slows gastric emptying in the elderly. Am J Med 118, 1289.

14. Jian ZJ \& Zhou BY (2008) Efficacy and safety of acarbose in the treatment of elderly patients with postprandial hypotension. Chin Med J (Engl) 121, 2054-2059.

15. Gentilcore D, Meyer JH, Rayner CK, et al. (2008) Gastric distension attenuates the hypotensive effect of intraduodenal glucose in healthy older subjects. Am J Physiol Regul Integr Comp Physiol 295, R472-R477.

16. Jones KL, O'Donovan D, Russo A, et al. (2005) Effects of drink volume and glucose load on gastric emptying and postprandial blood pressure in healthy older subjects. Am J Physiol Gastrointest Liver Physiol 289, G240-G248.

17. Jones KL, Tonkin A, Horowitz M, et al. (1998) Rate of gastric emptying is a determinant of postprandial hypotension in non-insulin-dependent diabetes mellitus. Clin Sci (Lond) 94, 65-70.

18. Borovicka J, Schwizer W, Guttmann G, et al. (2000) Role of lipase in the regulation of postprandial gastric acid secretion and emptying of fat in humans: a study with orlistat, a highly specific lipase inhibitor. Gut 46, 774-781.

19. Chaikomin R, Russo A, Rayner CK, et al. (2006) Effects of lipase inhibition on gastric emptying and alcohol absorption in healthy subjects. Br J Nutr 96, 883-887.

20. Schwizer W, Asal K, Kreiss C, et al. (1997) Role of lipase in the regulation of upper gastrointestinal function in humans. Am J Physiol 273, G612-G620.

21. O'Donovan D, Horowitz M, Russo A, et al. (2004) Effects of lipase inhibition on gastric emptying of, and on the glycaemic, insulin and cardiovascular responses to, a high-fat/ carbohydrate meal in type 2 diabetes. Diabetologia $\mathbf{4 7}$, 2208-2214.

22. Gentilcore D, Doran S, Meyer JH, et al. (2006) Effects of intraduodenal glucose concentration on blood pressure and heart rate in healthy older subjects. Dig Dis Sci 51, 652-656

23. Gentilcore D, Visvanathan R, Russo A, et al. (2005) Role of nitric oxide mechanisms in gastric emptying of, and the blood pressure and glycemic responses to, oral glucose in healthy older subjects. Am J Physiol Gastrointest Liver Physiol 288, G1227-G1232.

24. O'Donovan D, Feinle C, Tonkin A, et al. (2002) Postprandial hypotension in response to duodenal glucose delivery in healthy older subjects. J Physiol 540, 673-679.

25. Heddle R, Collins PJ, Dent J, et al. (1989) Motor mechanisms associated with slowing of the gastric emptying of a solid meal by an intraduodenal lipid infusion. J Gastroenterol Hepatol 4, 437-447.

26. Gentilcore D, Hausken T, Meyer JH, et al. (2008) Effects of intraduodenal glucose, fat, and protein on blood pressure, heart rate, and splanchnic blood flow in healthy older subjects. Am J Clin Nutr 87, 156-161.

27. Hveem K, Jones KL, Chatterton BE, et al. (1996) Scintigraphic measurement of gastric emptying and ultrasonographic assessment of antral area: relation to appetite. Gut $\mathbf{3 8}$, $816-821$.

28. Jones KL, Doran SM, Hveem K, et al. (1997) Relation between postprandial satiation and antral area in normal subjects. Am J Clin Nutr 66, 127-132.

29. Hveem K, Hausken T \& Berstad A (1994) Ultrasonographic assessment of fasting liquid content in the human stomach. Scand J Gastroenterol 29, 786-789.

30. Perko MJ (2001) Duplex ultrasound for assessment of superior mesenteric artery blood flow. Eur J Vasc Endovasc Surg 21, 106-117.

31. Piha SJ (1991) Cardiovascular autonomic reflex tests: normal responses and age-related reference values. Clin Physiol 11, 277-290.

32. Ewing DJ \& Clarke BF (1982) Diagnosis and management of diabetic autonomic neuropathy. Br Med J (Clin Res Ed) 285 , 916-918.

33. Feinle C, O'Donovan D, Doran S, et al. (2003) Effects of fat digestion on appetite, APD motility, and gut hormones in response to duodenal fat infusion in humans. Am J Physiol Gastrointest Liver Physiol 284, G798-G807.

34. Matzinger D, Degen L, Drewe J, et al. (2000) The role of long chain fatty acids in regulating food intake and cholecystokinin release in humans. Gut 46, 688-693.

35. Hildebrand P, Petrig C, Burckhardt B, et al. (1998) Hydrolysis of dietary fat by pancreatic lipase stimulates cholecystokinin release. Gastroenterology 114, 123-129.

36. Feinle-Bisset C, Patterson M, Ghatei MA, et al. (2005) Fat digestion is required for suppression of ghrelin and stimulation of peptide YY and pancreatic polypeptide secretion by intraduodenal lipid. Am J Physiol Endocrinol Metab 289, E948-E953.

37. Carney BI, Jones KL, Horowitz M, et al. (1995) Gastric emptying of oil and aqueous meal components in pancreatic insufficiency: effects of posture and on appetite. $\mathrm{Am} \mathrm{J}$ Physiol 268, G925-G932.

38. Cunningham KM \& Read NW (1989) The effect of incorporating fat into different components of a meal on gastric emptying and postprandial blood glucose and insulin responses. Br J Nutr 61, 285-290.

39. Horowitz M, O'Donovan D, Jones KL, et al. (2002) Gastric emptying in diabetes: clinical significance and treatment. Diabet Med 19, 177-194.

40. Horowitz M, Jones K, Edelbroek MA, et al. (1993) The effect of posture on gastric emptying and intragastric distribution of oil and aqueous meal components and appetite. Gastroenterology 105, 382-390.

41. Shepard TY, Jensen DR, Blotner S, et al. (2000) Orlistat fails to alter postprandial plasma lipid excursions or plasma lipases in normal-weight male volunteers. Int $\mathrm{J}$ Obes Relat Metab Disord 24, 187-194.

42. Suter PM, Marmier G, Veya-Linder C, et al. (2005) Effect of orlistat on postprandial lipemia, NMR lipoprotein subclass profiles and particle size. Atherosclerosis 180, 127-135.

43. Sahin M, Tanaci N, Yucel M, et al. (2007) The effect of singledose orlistat on postprandial serum glucose, insulin and glucagon-like peptide-1 levels in nondiabetic obese patients. Clin Endocrinol (Oxf) 67, 346-350.

44. O'Donovan D, Feinle-Bisset C, Wishart J, et al. (2003) Lipase inhibition attenuates the acute inhibitory effects of oral fat on food intake in healthy subjects. Br J Nutr 90, 849-852.

45. Di Marco M, Marier JF, Ducharme MP, et al. (2008) Pharmacodynamic equivalence of two orlistat capsule formulations in healthy volunteers under fed conditions. Int J Clin Pharmacol Ther 46, 319-326. 